\title{
Transition online: challenges and achievements
}

Jonathan Andrews

University of Birmingham, UK

Keywords: online; hybrid; face-to-face; academic skills; EDI; Covid-19.

\section{The challenge}

\section{Mid-March 2020}

Within a week of lockdown being seriously discussed, could a whole Academic and Digital Skills Division still provide the student support which was previously dependent on a significant campus presence?

\section{Could we keep going?}

In our Division, we provide assistance with study needs, such as digital skills, academic writing, revision, literature searching, and referencing. Skills advisors are from four main backgrounds: digital training; language and literature teaching; maths; and subject librarianship. The Division covers all undergraduate and taught postgraduate programmes and demand is high: 665 individual student-advisor appointments were held for the academic year 2019-20, terms one and two (before the March 2020 lockdown); 746 enquiries, including email; and 279 programme-embedded workshops or lectures from Autumn 2019 to 18 March 2020, with 13,545 students attending. The new institutional Scholar scheme and peer-assisted study sessions (PASS) provide significant integrated widening participation and learning support, including two extra one-to-one skills appointments. Both are normally campus-based. Prior to lockdown online provision was chiefly through LibGuides and Canvas (VLE), while face-to-face support was substantially in the form of workshops on campus. Students booked one-to-one help in Library appointment rooms. 
In the middle of the pandemic, the killing of George Floyd made world headlines and affected many with its exposure of profound inequalities and systemic racism. As Academic Skills practitioners, continuing to support students in online transition, how could we respond?

So - how to keep going?

\section{The response}

With the whole Division off-campus, an early decision was made to replace face-to-face workshops, designed for computer clusters and classrooms, with hour-long online Question-and-Answer ( $Q$ and A) sessions. PowerPoints, Word documents, LibGuides, and VLE (Canvas) modules were offered to programmes in advance. This enabled a move to flipped learning, which had previously been hard to achieve. $Q$ and As using Zoom video conferencing software reinforced advance resources with an introductory presentation, followed by students' questions and advisors' responses. This used dialogic learning as an online alternative to face-to-face workshops, in turn pointing to a future blended learning model (Petronzi and Petronzi, 2020).

Divisional staff all had work laptops, though adjustment to home working was not always seamless! Zoom was unknown before, which meant a learning curve. Some staff were at ease with doing multiple video recordings (Panopto), others initially less so.

We benefitted from having a substantial bank of materials from our existing provision for programmes. For example, VLE pages with links, PowerPoints, and text have been provided for first year medical students for several years or more: these simply needed updating. A lecture was replaced with a Panopto recording and an updated activity-based LibGuide, followed by $Q$ and As, to reinforce these materials and enable queries.

Colleagues have worked hard at extending and promoting our suite of online guides, videos, and innovative podcasts. One colleague used her smartphone to film 'Taking a break' outside her home: others recorded 'Google Scholar' on Zoom. 
The Division provides multi-disciplinary drop-ins and workshops. These have also been delivered as $Q$ and $A s$ over the last year. Events are now provided online for revision and assessment weeks. The net result is to extend support, provide flexibility for students, and effectively triage queries.

With a colleague's guidance, we are undertaking training and self-education (Ugoala, 2020), and expanding existing or creating new training materials - online resource lists and audio-visual playlists, LibGuides, and VLE content - to promote Equality, Diversity, and Inclusion (EDI). Our Q and As and our individual appointments increasingly use examples of diversity topics in supporting students and staff and visibly promote inclusion in an online environment. EDI is a standing agenda item in online team meetings.

\section{Easier said than done?}

There were practical and psychological challenges involved in setting up online sessions on an unfamiliar platform, against the backdrop of a pandemic. However, anxieties were shared by many others, nationally and internationally, and still overcome or alleviated (Ghazi-Saidi et al., 2020).

All of us want to support the students and staff. Especially at appointments we could see the immense pressures for our students (and tutors) maintaining and balancing home, study, and work. Feedback from appointments showed the value to students of maintaining contact: '[it] reaffirmed that I am where I am supposed to be and I can do it'; '[I] feel more confident and enabled'. Our efforts thus bore fruit in the way intended. Two $Q$ and As drew 136 first year Medical students; their Information Skills VLE page had 1.3K views (September to May). 1,009 one-to-one appointments were held online or by email between April 2020 and 15 June 2021, with fewer no-shows than when on campus: online seems easier to attend and attendance is more reliable.

Regular formal and informal online video conferences (Zoom, Teams), chats, and gettogethers provided mutual support.

Achieved:

- Learning materials maintained or developed for Programmes' VLE.

- $Q$ and As provided in almost all cases. 
- Experimental approach backed by positive feedback and attendance figures.

- Further widening participation support: Scholar Scheme.

- Greater recognition of our LibGuides, and increased VLE access.

\section{Recommendations}

All of us missed campus at some stage. However, for those with commitments or commutes, some home-working can be welcome.

Is it time to blend online and on-site support for the long-term? This may be necessitated anyway by an ongoing pandemic, but it could also better suit on-campus students with tight timetables, distance learners, or international students temporarily unable to travel (Kanwar and Carr, 2020). In fact, a hybrid approach combines the flexibility of online learning with the 'embodied and communal experience' on-campus (Eringfeld, 2021, p. $147)$ and even assists inclusivity and diversity (Eringfeld, 2021, p. 154).

The online shift can be exploited to develop flipped learning, with synchronous group delivery used to discuss queries and reinforce material provided in advance. One-to-ones allow for detailed discussion of individual requirements. Embedded VLE material, LibGuides, and targeted videos thus facilitate flexible, blended delivery by video conferencing or on campus.

Hybrid working may be a model forced by circumstance. It can also be an advantage to match modern lives and ways of studying.

\section{References}

Eringfeld, S. (2021) 'Higher education and its post-coronial future: utopian hopes and dystopian fears at Cambridge university during Covid-19', Studies in Higher Education, 46(1), pp. 146-157. https://doi.org/10.1080/03075079.2020.1859681.

Ghazi-Saidi, L., Criffield, A., Kracl, C. L., McKelvey, M., Obasi, S. N. and Vu, P. (2020) 'Moving from face-to-face to remote instruction in a higher education institution 
during a pandemic: multiple case studies', International Journal of Technology in Education and Science, 4(4), pp. 370-383. https://doi.org/10.46328/ijtes.v4i4.169.

Kanwar, A. and Carr, A. (2020) 'The impact of Covid-19 on international higher education: new models for the new normal', Journal of Learning for Development, 7(3), pp. 326-333. Available at: https://j|4d.org/index.php/ejl4d/article/view/467 (Accessed: 29 July 2021).

Ugoala, O. (2020) 'How to be a true ally' [Facebook] 3 June 2021. Available at: https://www.facebook.com/www.JOE.co.uk/videos/how-to-become-a-trueally/579944189573777/ (Accessed: 17 June 2021)

Petronzi, R. and Petronzi, D. (2020) 'The online and campus (oac) model as a sustainable blended approach to teaching and learning in higher education: a response to COVID-19', Journal of Pedagogical Research, 4(4), pp. 498-507. https://doi.org/10.33902/JPR.2020064475.

\section{Acknowledgements}

Thanks to ADSC managers and colleagues for their informed guidance on this piece.

\section{Author details}

Jonathan Andrews is an Academic Skills Advisor at the University of Birmingham. He has a background in librarianship and was the Library's Subject Advisor for Medicine. Since March 2020 he has been working remotely from home. 